\title{
Semiotic Analysis of Media ANd Visual Jihad of ISIS Group IN PhOtOS RELEASED BY THEM
}

\author{
Majid Movahed \\ University of Shiraz, Shiraz, Iran \\ mmovahed@rose.shirazu.ac.ir \\ Zainab Niknejat \\ University of Shiraz, Shiraz, Iran \\ zniknejat@yhoo.com
}

\begin{abstract}
Jihad is a central but variable concept in the Islamic fundamentalism discourse. The Islamic State of Iraq and Syria (ISIS) as the latest product of this discourse defined media jihad as an important aspect of this obligation by conceptual and exemplary development of jihad. In this research, by applying social semiotic method, authors have tried to analysis media jihad of ISIS group by semiotic analysis of their published photographs. Authors also have made effort to discover the intrinsic meaning of ISIS on this concept. By committing themselves to social semiotics presumptions, the authors tried to explore underlying layers of photos and reveal the social and cultural contexts, as well as power relations as the background of this semiotics. In this study, some codes such as companionship of ISIS soldiers with visual and media tools, companionship of media and visual tools with military and violent weapons and active participation of women in the jihad media, which consists of a system of signs were analyzed and such analyses were discussed in social and cultural contexts such as power, dual space, and switch from writing to image. Finally, the meaning that is generally understood of media jihad was quite different from what exists in Islam about jihad.
\end{abstract}

Keywords: Jihad, media, ISIS Group, photo

\section{INTRODUCTION}

What is considered by the authors of this article as a complex issue is the quality of media activities, especially visual activities of ISIS. The quality of treatment given to the media by ISIS, social and cultural conditions that have laid the groundwork for such treatment, and the merging ideological principles with their imagery, can be problematic. The conduction of semiology on the content of ISIS media is based on some resources, and understanding these resources through underlying text layers will cause deeper understanding towards their published images consequently leading to greater understanding of the Islamic Jihad group. 
In this research, efforts were made to study some of the photos published by ISIS related to media activities, especially imagery activities, bearing in mind the huge volume of images published on their behalf - prepared with other various subjects. Also by enjoying the social semiotic approach, the manner and dimensions of media and visual activity of ISIS was analyzed. Social semiotics is a method used to study the signs that are made in a specific social and cultural context, and power footprint can be scrutinized in making and spreading such signs. The objectives of this study include as follows:

1. Discovering the meaning of media and visual activity of ISIS in their photos.

2. Investigating the social and cultural contexts of such meaning.

\section{FUNDAMENTALISM, JIHAD AND MEDIA}

Fundamentalism is one of the startling developments of the late twentieth century in the world and has emerged in all the great religions derived from a series of booklets entitled 'Foundations' which were published by American conservative Protestants in the twentieth century. Today, fundamentalism refers to the efforts inspired by religious scriptures to stand against secular trends (Lechner, 1998: 196; Armstrong, 2000: 5). In fact, fundamentalism is a return to religious basics in which a group of believers engage in reactive actions by emphasizing certain features in their religion, which strengthen the identity and unity of their movement (Castells, 2003: 30). One of the most important features of religious fundamentalism is selectivity. In selectivity, aspects of religion and sacred scripts are selected, making them more efficient at war with modernity, with an exaggerated emphasis on them (Weinberg and Pedahzur, 2005: 5).

Although fundamentalism has emerged in most world religions, it is much highlighted in Islam and has been reflected more on media. One of the newest offspring of Islamic fundamentalism is ISIS Takfiri group, which is among the most controversial fundamentalist groups. ISIS is not only a terroristic entity, but it is the result of a creative and radical interpretation of Islam as a political philosophy (Friedland, 2015: 6).

In Islamic fundamentalism, jihad is a key aspect that is very important in understanding their performance and fights. Exaggerated emphasis of Islamic fundamentalists such as ISIS, on jihad, and expanding an exemplary concept of it, are among the selective performance of such fundamentalists against religion. According to the Islamic fundamentalists, achieving a religious order requires a global expunction, and barriers to promoting Islam, namely, states, social systems, traditions and even believers of other religions, should be eliminated. Excommunication and declaring hatred towards such obstacles sentence their annihilation, and it is believed that one way to establish Islamic order in the world is to organize a comprehensive jihad against all ignorant societies, namely, Christians, Jews, Communists and apostates and atheists Muslims (Dekmijian, 1987: 72). So jihadism represents the ideology of ISIS fundamentalist groups, and taking an aggressive approach towards jihad is considered as the turning point of such ideology (Bunzel, 2015: 7, 10).

Although Armstrong (2000) considers fundamentalism as a response and resistance to extreme modernization; this phenomenon is referred to as the offspring of modernity, a child who isn't a stranger to his mother. As fundamentalists in dealing with their sacred scriptures take inventive and selective interpretations, they also take a selective approach in dealing with modernity; they admit technology and its scientific achievements, but reject 
the modernity values which are threatening to their identity (Dadosky, 2007: 515). Mass media is among the modern elements that are frequently used by fundamentalist groups. It enables them to produce and publish their intended literature and implications. The media has always been an important hanger for religious fundamentalists to advertise truth, mass mobilization, the protection of believers and challenging of non-believers. "The media types used by fundamentalists vary according to their formation time, as well as the technology available to them. According to the global mission considered, the most advanced technology at that time is used to achieve their goals" (Thomas, 2014: 77; Hamidizadeh, 2014: 76).

Globalization elements such as internet have assisted these fundamentalists to step beyond their local boundaries by their omnipresence nature and freedom of action, and transmit their messages at a level broader than local context. This is effective in creating like-minded virtual networks around the world (Karaflogka, 2006: 25-24; Heriot, 2009: 25). In addition, individuals and extremist groups have found online space, as a cheap, safe and convenient environment for their communications. Cyberspace has several advantages such as easy access, anonymity, fast tracking of information, rule freeness, government censorship and surveillance, and in particular mass audience, video, audio, photos, posters etc. can be easily uploaded and downloaded (Winkler and Dabr, 2014: 2).

Fundamentalists can employ media as success or failure generators of religious messages and lay the groundwork for conscious or unconscious construction of various religious meanings such as jihad. Here the media can serve religion both in the process of creating symbols and their interpretation (Hur and Landbay, 2003: 14). In other words, if a group or movement is to find a global position and prosperity, then its organizations and institutions should be accompanied with global media which are dependent on the internet, should compete with similar groups in the production and publication of content, and at the same time accept the risk of change in their nature (Karaflogka, 2006: 14).

\section{Change of Jihad Models}

In the Qur'an, there are many verses about the importance of jihad. Islamic Jihad is a legitimate and fair war engaged in for the survival of the Islamic community, preserving its existence and spreading human values rather than geographic expansion and conquest and imposition of religious belief (Barzenoni, 2005: 150). In the Qur'an and tradition of the Prophet, Jihad is not only legislated, but also its related regulations have been described. Jihad should be in the path of God, its tools should be legitimate, warriors need to observe virtue and even treat their enemies with fairness. Jihad in Islam means killing someone who first intended to kill, and this should be done in the way of and with proximity to Allah (Haghpanah, 2009: 103).

It is noteworthy that differences exist between Shiite and Sunni (two dominant sect of Islam) in the concept of Jihad; however, the two streams together agree that jihad has laws and rules. First, the Quran begins this right by inviting, then wants Muslims to defend their territory and then turn to fight, and there is also great flexibility in this fight (Moradi, 2014). It should be noted that according to Islamic scriptures, jihad with one's self is the highest level of jihad which refers to the attention of individual to themselves and modification of their psychological and behavioral evils and deviations.

With the formation of Takfiri and Salafi sects out of the heart of Sunni sect, new views were formed for jihad. This redefinition promoted jihad to the basics of the religion, and by magnifying issues about jihad, substitutes it with a criterion such as virtue for evaluation of Muslims. As mentioned, this issue arises from the selectivity characteristics of fundamentalists. 
By presenting a new and caricature figure of jihad, this obligation became the most important slogan of Islam and thus, it turned into a basis for contemporary radical Islamism (Bakhshi Sheykh Ahmad, 2006: 197). In definitions provided by Takfiri fundamentalist leaders, jihad is limited to violent jihad in the military field, and sword and battle with enemies is defined as the sole way to promote Islam (Fateminejad, 2013: 37).

Fundamentalists' theoretical definition of jihad and what is practically common as jihad among them is significantly different from the definition of the original Islamic Jihad. However, there has been no constant procedure for fundamentalism and extreme definitions of jihad. With the expansion of the activities of Islamic fundamentalist groups, the traditional model of Jihad, which was an armed and violent activity, got changed and their leaders became interested in diverse models of jihad. A clear example of this issue is the definition of areas such as media jihad, marriage jihad, engineering jihad, children's Jihad and medical jihad (human organ trafficking and treating of soldiers) etc. in the ISIS Takfiri group, which is based on deviated interpretation of Islamic religious sources. Such new models of jihad are being performed parallel to armed jihad, and the footprint of violence and aggressiveness can be seen in them (Dideban, 2015).

The foregoing lines discuss the importance of the media, in particular cyberspace, for fundamentalists. In the meantime, the volume of imagery texts published is significant, and in the meantime, images with photographic aspect have an important centrality. At the beginning of the rise of Islamic fundamentalism in the 19th century, fundamentalists considered imagery as idolatry and prohibited it. Visual representations by fundamentalists over two centuries have experienced a troublesome path and was affected by two major perspectives: Based on the first view, which is affected by Wahhabism, imagery like coffee, cigarettes, etc. as heresy, was considered totally prohibited. Another view which is influenced by the teachings of Mohammad 'Abdu (1905-1849) and Rashid Reza (1935-1865), is that, while rejecting the idolatry, they showed more tolerance toward imagery and a variety of visual representations. The recent view was adopted by Palestinian resistance groups. In this century, Wahhabi approach towards the imagery bans has dramatically shifted and in the neo-Wahhabi groups such as al-Qaeda which is a follower of Wahhabism traditions, imagery has gradually been dominated (Kovacs, 2015). Through the increased significance of the image in the news reports and the capability of photos in affecting the audience's ideology (Storm, 2106: 156), in ISIS, a rotational theory is emerged in this field towards their predecessors, and imagery representations with its various forms have spread deeply in this group, and have allocated a major part of the media activities to themselves.

\section{METHODOLOGY: SOCIAL SEMIOTICS}

All the visual and non-visual texts encountered through living in human society are understandable as a semantic entity, which were constructed and signified in a political and social context (Adegoju, 2016: 7). Social semiotics is a combination of modern views on social meaning and action, and deals with social resources of individuals in communication and production of meaning. Social semiotics which are affected by Roland Barthes approach has highlighted the role of culture in mining the meaning and follows the power footprint in the representation of events. This methodology, in addition to the systematic investigation of signs, deals with the use of signs by people in their relationships. Since different communities differ from each other, their signs and application are also different. In addition, in the field 
of image, social semiotics seeks to understand how the image language is used in social processes and deals with discovering the power relationships and available hidden layers of meaning (Harrison, 2003: 48; Hassanpour, 2012: 18-17).

In this study, the semantic framework of Kress and Van Leeuwen was applied, and efforts were made to obtain general propositions and arguments through close reading of photos and gaining partial information. Kress and Van Leeuwen's semiotics framework seek to discover structures in the study of data to uncover the ideology governing those structures and analyze the socio-political contexts that underlie these structures. Kress and Van Leeuwen considered seven methods of constructing semiotics in photo readings, which provided a good basis for studying the photos of this research:

1. People and places represented in the photo.

2. The gaze of the people represented to the audience (whether or not they have direct eye contact with the audience).

3. Frame size that includes close shots, medium shot, and long shot.

4. Vertical or horizontal framing, each of which has a separate partition. The horizontal box involves a straight angle in which the participant directly encounters the audience, or implies the diagonal and indirect angle in which the participant avoids contact with the audience. In the perspective of the viewer, vertical framing falls under the high vertical angle, low vertical and eye level.

5. Position of the photography subject at the center or border of the photo.

6. Analysis of each of the above-mentioned constructs in relation to socio-political foundations and the discovery of the ideology governing photographic structures (Storm, 2016: 157).

In social semiotics, signs are made rather than being merely used. The process ofsemiotics is the difference among social semiotics and semiotics in other areas. In this area, people with their social character with the aid of cultural resources, build a sign. Unlike most linguistic theories that seek to separate form and meaning, social semiotics does not separate them and considers them as a whole (sign). These meanings reflect the social system and its changes (Nikoubakht et al., 2011: 223). The culture is the platform of production of meaning and is present across all social relations. However, the meaning is always partly dependent on structures, because resources and grounds are effective on semiotics. But the structures do not have a completely determining role in meanings. Decoding by audiences and readers is a dynamic factor that prevents the static mode in the meaning as well (Davis, 2002, quoted by Khaleghpanah, 2009: 168). Social semiotics emphatically points out that signs are built in a certain position and for a certain purpose, and all the stages for building signs are shaped based on the interests of its builders. Therefore, assignment of semiotics processes to others means allowing others to take control of the world by producing and publishing literature for their own benefits (Vannini, 2007: 116; Kress, 2013: 75; Chandler, 2008: 38).

The source is one of the main aspects of social semiotics. Semiotic resources are complex structures of signs, having a variety of meaning potentials within themselves, and providing people with it. Using the source avoids the idea that a sign is preset and is unaffected by its users (Van Leven, 2005: 3). Each culture has its own semiotic resources that lay the groundwork for forming and creating the signs, and without such formation meanings cannot be transferable and understood. Cultures in this field have a different approach. In 
semiotics point of view, cultures and spaces all have a rich culture and, in this regard, there is no difference between first and third world, between East and West etc., because each one has a different semiotic and cultural richness (Kress, 2013: 22-20)

The most important action of signs is encoding, which eventually leads to the discovery of signifier references or decoding. Therefore, any sign acts within a system of encoding, references and decoding. Social codes speak about the people, groups and relations between them. Signs turn codes into meaningful systems that are linked to each other in the framework of this signifier and signified system, consequently produce and reproduce meanings. The universe makes sense for any culture within this code system and allows people to exchange their experiences. Denotation and connotation also make sense in this system. The connotation contrary to the denotation is more open, unlimited, polysemic and evolved, and this should not be considered identical with semantic pluralism. Each society imposes a certain classification on its signs, meanings and issues, and thus creates a dominant cultural order (Khaleghpanah, 2009: 172-169).

The population studied for this research included photos published by ISIS fundamentalist group loaded in cyberspace, websites and online magazine of ISIS published and replicated in such space. Since the authors seek a deep understanding of the subject matter, a method of sampling that provides rich information was employed. Thus, the purposive sampling was used in which a small group of samples were selected on the basis of their features and to gain more information. Photos in this study were selected with regard to research questions from website of Intelligence, New York Times, Aperture, Dabiq and Wordmake.

\section{The Research Procedure}

Social semiotics is flexible in terms of structure and procedures, and elements and components were formed during the research. Thus, a research done on the basis of semiotic methodology is a relatively free and unstructured research, and follows a spiral, reciprocating and indirect path. Thus, this study did not follow pre-determined and sequential steps (Iman, 2012: 175174).

The central concept of this study - the analysis of which is done around it - is the media activity of ISIS with an emphasis on the imagery and photographic media. The concept of media jihad determines dealing with signs and has closed exposure to the other concepts and codes presented in the form of signs, and codes to the researcher, therefore, the steps of this research was not completely without structure. Once the codes related to media jihad - such as using computer and photography and their decoding were found, then the signs building those codes were identified. The researcher meant to achieve the underside and underlying meaning of the signs after understanding the initial implications in the relationship between signifier and signified. In other words, the primary meaning is considered as a signifier which has a hidden signified and the social semiotics should reveal the signified as much as possible. Sometimes semiotics uses symbolic signs in making the texts. In the meantime, the researcher tried to describe the historical references of such symbols and clarify its role in meaning making. Since social semiotics focuses on the use of resources by groups and individuals, the researcher attempted to refer to resources in which ISIS group took advantage in the semiotics of its intended photos.

In this study, the researcher made an attempt to achieve the mental meaning of media jihad that was hidden in the photographic literature through analyzing the signs that the 
actors (ISIS) have produced, and this required that the desired concept from the views of sign producers should be dealt with. Since it was the ISIS who gave meaning to the concept, therefore the researcher tried to sympathize with them without unifying with them (Delavare, 2011: 272). The researcher also decided to investigate the question of power in connection with the intended meaning according to the methodological commitment to explore relations of power, and focus on it during data analysis.

\section{ANALYSIS OF THE RESEARCH RESULTS}

An important code seen in the photographs of ISIS with a focus on media and imagery activities is the engagement of ISIS soldiers with computer, cameras and smart phones, which are the most important tools for broadcasting or becoming imagery. Although a huge amount of photos (with a variety of subjects such as children, daily life, military activities, slaughtering heretics and sinners, etc.), videos and texts combined with photos in themselves signify their widespread media activity, when these activities and tools become the photographic object, in fact, it shows an emphasis besides which a new field of jihad is being introduced to the audience.

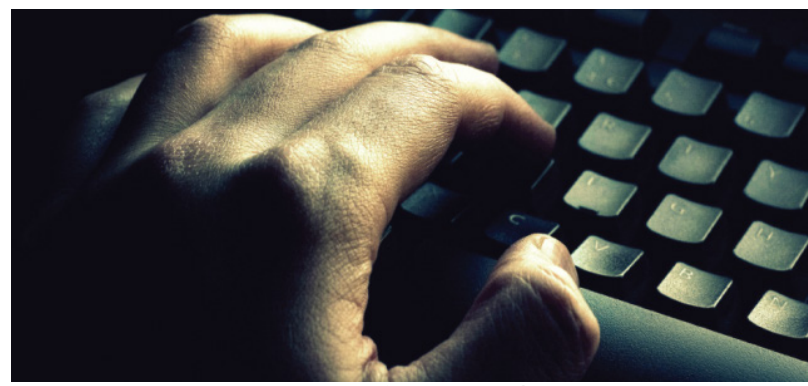

Photo 1: Dabiq, 1435/10, p: 27

(Source: http://www.clarionproject.org/news/islamic-state-isis-isil-propagandamagazine-dabiq)

Photo 1, as published in the Dabiqe magazine, can be viewed as an illustration of what the ISIS group is offering. Shooting in the Insert viewport, which reduces the overall subject matter to a partial thing adds to the mysterious timelessness of the image. Although there is no direct eye contact in this picture, contact with the audience was not cut off completely.

Fingers on the keyboard represent communication with the audience which can be masses of unknown people, a relation which is of the media type. The frame size is CloseShot, and instead of representing the entire subject, it represents only his hands, and displays the overall view of the computer only by displaying its keyboards. Discarding the overall representation and focusing on two elements that are symbols of power (hand) and communication (keyboard), these signs referred to ISIS media authority.

In Photo 2, people who are represented are members of the ISIS group. A number of ISIS men who are often faded and one person in the focus mode displayed at the center of the image. They stand like a mass close to one another and, without direct eye contact with the audience; they present themselves to their global audience by holding their smartphone and professional photography camera. Disregarding the audience, they stand evenly in one direction, and out of the ten who can be seen, three people are working with the media, and 
all are hunted by another camera and on a medium shot. The hunter cam took pictures in a vertical and high angle, while dominant in the situation. Using the high focal length presents people more compact and having lesser distances and unified, than what actually exists. The media-centeredness of the ISIS group, implicitly referred to as unity and integrity, is presented as their most significant feature in this photo. Position of the camera man in the center of the image, while carrying apparently contradictory signs such as beard, keffiyeh, camera and non-traditional clothing, indicates the significance of having this addition together. Holding the media, especially visual media, as it is centralized in the image, is also significant in the ISIS ideology. However, on the sidelines, there are people with mobile phones who are apparently filming. Such omnipresence is the characteristics of the ISIS media.

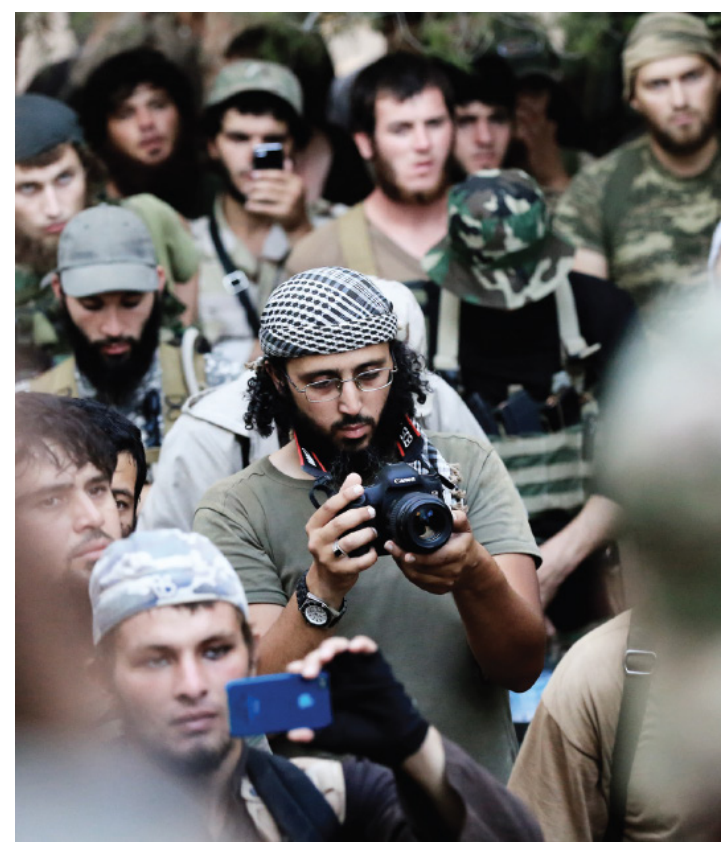

Photo 2: Dabiq, 1435/10, P: 22

(Source: http://www.clarionproject.org/news/islamic-state-isis-isil-propagandamagazine-dabiq)

In conditions where the image of ISIS is illustrated and their media nature is broadcasted, as if the curtain is lifted from a jihad, where modern tools are captured by ISIS, this helps them in their jihad. Being modern and reactionary, is a contradiction that gathering together is only under the flag of Jihad, and although apparently eternal enemies, the two establish such a strong connection with each other, as if the rest of this reactionary jihad is possible only with the help of modern tools such as media and image. This media such as a full-length mirror visually represents the events and moments of Takfiris and in addition to demonstrating what really exists, is likely to represent something that does not actually exist or does not have a frequent existence. So by building signs in order to bring modern media tools on their knees, introducing the field of media jihad, and being omnipresent through the media, the ISIS tries to consciously or unconsciously direct the audience toward a path to consider them as something hyperreal. 
Among the many images of the ISIS group in cyberspace, there are photos such as Photo 3 without human subject, but include humanitarian instruments that are of primary significance to the ISIS group. Again, if there is no human being in the picture to interact with the audience by staring at the camera, then there is a tool that is a symbol of human communication: a mobile phone with a clear screen and a social network. It implies that they are always on and online!

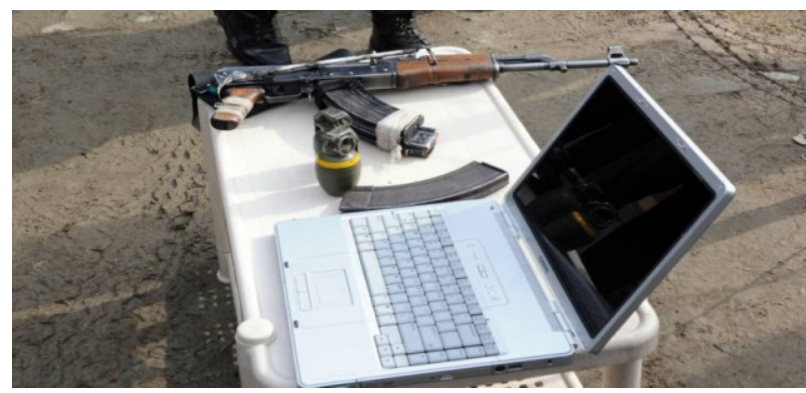

Photo 3: Wordmake, 08/30/2014(page 7 para: 3)

(Source: https://mic.com/articles/97690/)

The shot is taken at the medium Shot View used to represent the relationship between the objects. Such a view, although not full of information about the environment, it fully pictures the captured subjects and the relationship between them. Vertical framing, emaciation and immobility turn the photographed elements into dynamic and active communication with each other and with the audience.

Another important code which is evident in photos is the companionship of media and imaging tools with military and violent weapons as guns, knives and even the use of symbolic guns instead of weapon. Coexistence of these two indicates a deep association of gun and the camera in jihad of ISIS. These are the two elements that make them not a decisive winner on the real battlefield, but the winner of media, and have infected websites and social networks with deadly images, ideological slogans and occasional threats. The companionship show of camera and weapon can suggest that ISIS media is as dangerous and important as their weapon and sword, and in addition to their military power, their skills and media power must also be addressed to the audience. Since no one is safe from the blade of ISIS (as they say), no event can hide from their camera lens and computer monitors. Although no element of the photo is exactly centered, the weapons, the knife and the cartridge have a more marginal role than the mobile device. Therefore, media can play a more central role in ISIS ideology.

In the meantime, the photo of an ISIS soldier having a camera in one hand like a gun and bullets on the other hand is one the most powerful publicized photo in this field (Photo 4). It is a symbolic behaviour which has fully merged the concept of violence, military and media activities.

Although the visual elements do not give a detailed description of the location of this image, the presence of the sky and the hills on the background suggests that this image is similar to many other ISIS photos in the natural environment. The person pictured in this photo is putting on military uniform and a red keffiyeh, representing pan-Arabism, Wahhabism, and Arab terrorism. This ISIS soldier looks daringly and directly into the camera. 
Although their face is covered by the keffiyeh and cannot communicate with the audience, their eyes are so influencing that they leave nothing to say. In addition to the eyes staring at the camera, the camera's eye (lens) also directly targets the audience. The kind of look shows that there is no connection between the audience and the person being photographed, not from the position of weakness, but from the equal position (the angle of the image is completely level), and invites the audience to this challenging connection. The vertical box contributed to enhance the stubbornness and stability of the image. The rows of cartridges that extend under the camera to the object hands and continued out of sight of the audience, is connected to the two left and right sides of the photo. The center of the photo is empty and does not provide a solid item; this directs the mind to the three main corners of the photo: eyes, camera and hands carrying bullets. The choice of medium-shot frame also creates a space like Western movies. Choosing this frame, along with the adoption of such a symbolic gesture has created a dramatic image, and this perhaps will make the audience think more than other pictures.

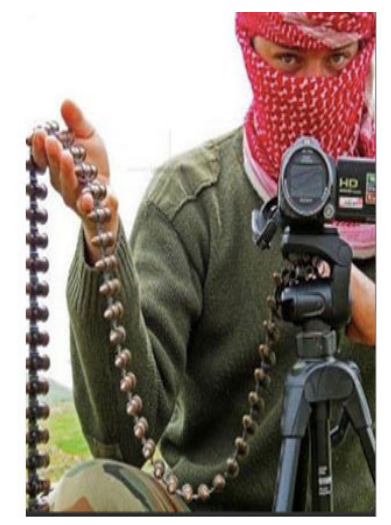

\section{Photo 4: Aperture, 12/11/2014}

(Source: http://aperture.org/blog/the-islamic-state-and-photography/)

As said in the foregoing lines that violence is considered as a very important feature of jihad defined by ISIS; a large number of images that clearly exhibit violent crimes is an evidence of what actually happened in real field of jihad, and their huge presence in cyberspace has entered jihad into media and contaminated websites, media and cyberspace to such texts. As Naji, a Takfiri thinker believes "those who have seen the use of violence in war and jihad field, won't forget about its use in the media" (Naji, 2006: 73). So as military jihad is full of violence, media jihad also contains symbolic and modern violence.

Another code seen in the photos was an ISIS woman using laptop, who was taken a picture with full coverage in the desert space with her laptop. This is while the shadow of the soldier standing next to her and his reflection in the laptop screen is visible; interestingly, the edge of her weapon is glaring beside her. In this image, the represented people do not make eye contact with the audience. One of the main features of ISIS women is to escape direct contact with the audience. They constantly remove their gaze from the audience, and of course, in most of the photographs, because of the use of masked and covered faces, the eyes are not clearly visible, yet there are fewer opportunities for women to communicate with the audience. The men also do not have direct contact with the audience, but his shadowy 
and obscure presence behind the woman is a significant codification in this photo. It is also featured in the medium shot, which can be considered as one of the most widely used frames in ISIS photography. A frame that does not completely disclose location features, but at the same time provides minimal information about the shooting environment; in addition, it facilitates the communication between objects that are photographed in a medium frame. The choice of the horizontal frame that reduces the picture's dynamics and adoption of a high angle suggests a top-down view towards the women to the audience. The composition of the photo is such that the woman and her laptop are considered as two basic elements in two key points of the photo, and this combination of mind and view orients the audience towards key elements of the photo.

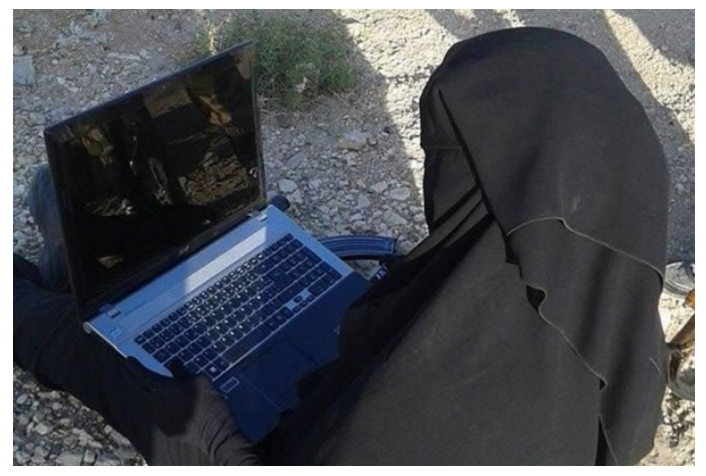

Photo 5: Intelligence Group, 11/11/2014

(Source: http://news.siteintelgroup.com/blog/index.php/categories/jihad/entry)

Such signs indicate the military jihad and with much greater emphasis, media jihad by women. But since semiotics has a commitment more than finding the early indication, the researcher explores within underlying such concepts. Women have always been considered as inferior beings through the narrow approaches of fundamentalism - a view that the mainstream of Islam totally rejects - and were kept quite limited in the back room of the house in social and non-military activities as well as in armed jihad. For example, Taliban, even limits women pedestrians on the street. Another example is the absence of women in the military operations of Al-Qaeda, the reason of which can be the dominance of conservative attitudes in Muslim societies that provided the context for al-Qaeda. But then gradually a radical shift was developed in the role of women in jihad (Cook, 2005: 383).

Today, in the images of ISIS, we witness an arena of women's jihad in media that is unprecedented in the life of fundamentalism, and this group has broadened the arena for women in jihad, unlike traditional views adopted by fundamentalist Muslim before them despite the narrow approaches of ISIS adopted in other sectors. In the ISIS media jihad, which is an integral part of armed jihad, women have rose and besides preserving the ideological considerations of ISIS - such as full and black coverage - have entered the field of jihad. In addition, the presence of weapon in the picture has a vague reference to the armed jihad of women and that even if it has not taken place in reality, but it flows in the media jihad and is flaunted to the world.

Women-men cooperation which is implicitly and vaguely referred in this photo is a fundamental change of approach. Getting out of the private sphere and cooperating with men 
in the software and media, originates from modern perspectives in relation to employment and social presence of women, and ISIS which on the one hand attacks the modern world and its elements, has entered this aspect of modern thinking in the definition of women's Jihad. However, the man in the photo, who is ambiguously reflected in the laptop screen and his shadow next to the woman is like an observer in a position beyond and above the woman and still maintained its superior position. Therefore, modern intellectual grounds are always among important grounds in semiotics of ISIS, which are also effective activities in dealing with signs.

It can be said that this jihad wave occurring today, has reproduced the rules governing all aspects of peoples' life under the government of ISIS as well as their soldiers according to ISIS ideology. Even the most personal relationships of warriors are formulated based on marriage jihad rules, and in the meantime, permanent engagement with imaging various aspects of the jihad and its reflection in the media itself has become a part of jihad. The omnipresence of cameras and recording jihadist events and commitment to releasing them in the virtual space is a part of a more global jihad, and since in its absence, the military jihad of ISIS remains sterilized, of course, it will be considered an important aspect, because an important part of advertising, recruitment, intimidation and indoctrination of surrendering to them is done by the media and photos.

As mentioned, meaning-making take place through a system of signs, according to some sources. It seems that the trend of globalization and tendency for accompanying with some aspects of the modern world are one of the main sources of these semiotics. However, semiotics action has occurred in an ideological context and taking into account the role of ideology, we can provide a better understanding of the relationship between the signifier and its signified in photos; because ideology is the fundamental beliefs that control and manage the representations of the ISIS groups (Storm, 2016:156). So, ideology is another important source for meaning creation of ISIS. Statements that Takfiri theorists provide by relying on Islamic sacred texts are ideological resources that are the grounds for producing the media texts. For example, "they believe that it is obligatory for warrior Muslims to use the media to achieve their goals" (Nejatpour et al., 2014: 98). This obligation has caused the group to follow their media activities very seriously and professionally and develop and make texts which are not understood for a small group, but for a global audience.

It should be noted that all media texts associated with ISIS, and reproducing and sharing them is not under the control of this group. An important feature of media jihad is that it is controlled by ISIS to some extent, and then the anonymous global audiences intentionally or unintentionally accompany it, and continue the jihad by duplicating and sharing ISIS Jihadi literature. Thus, if there is an end to armed jihad, media jihad is an endless jihad that can be used as a hyperreal, and be continued regardless of what happens in the real world.

\section{DISCUSSION AND CONCLUSION}

What was said through semiotic analysis of the concept of media jihad with an emphasis on the photographic activities to the ISIS was the result of reading the signs that have been made in the social and cultural context; signs that have simply not been used but also made by people in a certain social context. Meaning is not formed in a vacuum, but is tied to the interests, social benefits and power relations of the group. Meanings and their internal relationships have an independent effect on social life, however, they themselves are creatures 
of social life of fighting people and are produced in such context (Seidman, 2013: 183). Contexts investigated in this study as social and cultural contexts, making meaning of media and visual jihad, included: power, dual space, and replacement from the text to the image.

\section{Power}

ISIS, first of all, seeks political power and changing power relations in favor of its own. Thus, in its selective resort of Islamic law it selects the doctrine that is most widely used in gaining power. Obviously, with emphasis and focus on the teachings of Islam which is based on balance, tolerance, peaceful coexistence etc., spiritual dimension of Jihad or jihad with the soul are excluded since they do not contribute to change the relations of power in their favor.

Media activities, first of all, can create a vision of a powerful group that is in fact deprived of power. But the same thought and meaning, with an impact on public opinion, paves the way for gaining true power. Thus, selection of Jihad and media and the integration of the two before anything can be considered as an attempt made by ISIS in order to change the balance of power in their favour and realizing the ideals of the Islamic caliphate.

\section{Dual Space}

In a dual space cyberspace, in which the virtual space has become a part of each process, religious fundamentalist groups are not limited to actual space and their activities, including jihad, which is considered their most important activities, has been expanded to the second space. The cyberspace has provided the ground for fundamentalist groups to forgive a crossborder feature to their fight. The aspects of Jihad that is taking place in cyberspace may be different from what happens in reality. The represented reality of jihad in cyberspace has been an exacerbated reality, which has more power and intensity than the real jihad. The field Jihad which is limited in terms of place and time, through cyberspace has found a fluidity that intensifies it in every time and place. "Cyberspace is a fast-moving, local-global, ultra-time and ultra-space. Not only is one fluid in the virtual space, but also information and information flow enjoy high fluidity. High motion power allows one to flow in space" (Ameli and Hajijafari, 2012: 99).

A fundamentalist group such as ISIS, which has developed its Jihad from real world to the virtual world, will keep its virtual jihad working, even when its jihad is stopped in the actual field. Thus, jihad with all its dimensions and characteristics becomes a fluid concept in virtual space, and cuts across geographical boundaries with the loss of time and place.

Jihad that occurs in the real world in a certain section, is reproduced and repeated in the virtual world in a repeated form, beyond time and space, and such repeated reproductions are out of the control of fundamentalist groups, because their publicized texts is available to the global audience and the cyberspace provides them with sharing and publishing the documents. For this reason, more people are involved in this virtual jihad. It is possible that jihad ends in the real world, but continues in cyberspace, with more range and longer duration and the number of those engaged in such a Jihad is increasing by the second. Jihad has a quiet and charming feature, but it gradually involves person, culture, nation and governments. It is a war which is turned from hardware to the war of symbols, signs, and codes (Ameli 2003: 27-26).

Now the ISIS fundamentalist group as the newest existence of religious fundamentalism has become a media, and instead of conquering the territories of the countries, it has turned 
to conquer the virtual space, and has filled out the news pages and social networks with its pictures. It was a turning point in Islamic fundamentalism, as previously we were witnessing fewer cases of visualization and media activities by fundamentalists under jihad in cyberspace.

\section{Switching from Writing to Image}

Some scholars, such as Lyotard and Baudrillard, believe that visualization is a feature of postmodernism, a section where the image gradually precedes the word, instead of expressing reality, it becomes the reality (Shahande, 2008; Malekafzali, 2008: 74). In this context, individuals and groups maintain visual references in different fields such as advertising, gaining power, informing, and memorizing the memories and so on. Thus, they have saturated the field with imagery texts more than ever; therefore, the communities are drowned "in a torrent of meaning diversity and cultural representation" (Seidman, 2013: 230). Images look like they are from reality, but are gradually being replaced.

ISIS fundamentalist group acts in this context which is affected by it, and is very dependent on visual representations. Their resort to shooting and producing video reports of their activities is rare among fundamentalists, so that it can be said that ISIS is the most religious fundamentalism flow. Hence, they are accompanied with the spirit of the time, based on visualization of culture by which they are also affected.

Photos and videos uploaded by the fundamentalists and quickly replicated is an important factor in the position of ISIS, their threats, illustration of different aspects of jihad and ultimately advancement of their goals as much as possible. Therefore, the use of visual texts in addition to more precise introduction of the identity of ISIS and description of visual aspects of their jihad has an important and operating role in achieving their objectives. It is possible that without submitting written texts, they could not have reached such luck, because the image is more understandable for people and covers a much wider range of audiences. However these images are similarities that gradually replace the truth of ISIS and attract the minds to their images instead of their own. Increase in visual representations in the media breaks the borders and blurs the boundaries between political activities, entertainment, news, etc. Thus, fundamentalists with increased visual activities must accept the risk of change in their nature in the media.

It should be noted that Islam is peaceful in nature and jihad as war is the last resort for believers. Jihad means to resist evil which flows in every area of life and this is quite different from the mercy and moderation that exists in this religion and is interconnected. However, Islam does not hide its approach about jihad as war and in the event of damage to the religion of Allah and the believers considers it and permits it with regard to rules. Although Jihad of ISIS group in the field of media as well as other areas - which requires separate research - is presented under the Islamic headings and terminology, but in fact, it is a very unlikely interpretation of Islam.

\section{REFERENCES}

Adegoju, A. (2016). We have to tell our own story: Semiotics of resisting negative stereotypes of Nigeria in the heart of Africa nation branding campaign. Social Semiotics, 27(2), 158-177. Ameli, S. (2003). Dual worlds and future of the world. Monthly Social Sciences, 69\&70, 15-28. 
Ameli, S. Haji Jafari, M. (2012). Dual space approach to virtual damages and religion: attitudes and experiences. Two Scientific Journals of Religion and communications, 19(1), 95-125. Armstrong, K. (2000). The Battle For God. New York: Alfred A.Knopf.

Bakhshi Sheikh Ahmad, M. (2006). Jihad: from Ibn Taymiyya to bin Laden. Strategy, 39, 193-214.

Barzenoni, M. (2005). Islam, originality of war or originality of peace? International Law, 33, 73-158.

Castells, M. (2003). The Information Age: Economy, Society and Culture, identity and power. Translation of Hassan Chavoshian, Tehran: Tarhe No.

Chandler, D. (2008). Foundations of semiotics. Translated by Mhadi Parsa, Tehran: Sureh Mehr Publications.

Cook, D. (2005). Women Fighting in Jihad? Studies in Conflict E Terrorism, 28, 375-384.

Dadosky, J. (2007, September 1). Sacralization, Secularization and Religious Fundamentalism. Sage. Retrieved from http://sir.sagepub.com/content/36/3-4/513

Dekmajyan, H. (1987). Islam in the Revolution: Islamic Movements of Iran in the Arab world. Translation of Habib Ahmad, Tehran: Keyhan.

Delavare, A. (2011). Theoretical and practical theories of the research in the humanities and social sciences. Tehran: Roshd.

Fateminezhad, M. (2013). Perceptions of al-Qaeda from jihadist ideas of Seyyed Qotb. Seraj Monir, 12, 31-52.

Friedland, E. (2015, Mey 10). "Special Report the Islamic state". Clarion Project. Retrieved from https://www.clarionproject.org/sites/default/files/islamic-state-isis-isil-factsheet-1. pdfHaghpanah, R. (2009). War and Peace from the viewpoint of Allameh Tabatabai, Research by the Islamic community, 75, 77-120.

Hamidi Zadeh, E. (2014). Media, an integrative element of fundamentalism. Management Communications, 54, 76-79.

Harrison, C. (2003). Visual Social Semiotics: Understanding How Still Images Make Meaning. Technical Communication, 50(1), 46-60.

Hassanpour, M. (2012). The representation of a social issue in the photo, a semiotic approach in understanding the processes of social representation. Culture and Media, 5, 15-29.

Herriot, P. (2009). Religious Fundamentalism Global, Local and Personal. Newyork and London: Routledge.

Hur, S., \& Landbay, N. (2003). Rethinking about the media, religion and culture. Translation by Masoud Aryayi Nia, Tehran: Soroush.

Iman, M. (2012). Philosophy of research methods in social science. Qom: Institute of Science and university.

Karaflogka, A. (2006). E-Religion.: London Equinox Publishing.

Kovaks, A. (2015). Visual Representation, Propaganda and Cyberspace: The case of Palestinian Islamism Movements. CyberOrient: 9(1).

Kress, G. (2013). Social semiotics, from theory to application, multifaceted representation of semiotic approach to the topic of communication in contemporary era. Translation by Sajjad Rahman Kabgani and Rahman Sahragard, Tehran: Marlik Publication.

Lechner, F.J. (1998). Fundamentalism in encyclopedia of religion and society. London: Sage. 
Malekafzali, F. (2008). Image culture. Light Courier, 3, 72-81.

Moradi, A. (2014, November 30). Takfiri jihadist foundations in Sunni and its criticism, Retrieved from Http:/Www.borhan.ir/Nsite/Fullstory/News/?Id=7958

Naji, A. (2006). Management of savagery. Translated by William McCants, United States: M. Onlin Institute.

Nejatpour, M., \&Milani, J., \&Nejat, A. (2014). The phenomenon of ISIS and media devices. Media Studies and Nation, 1(1), 89-101.

Nikoubakht, N., Desp, A ,. Bozorg Bigdeli, S., \&Monshizadeh, M. (2011). Model for woman transformation from the role of home wife to a social reformer based on social semiotics and Shoon novel and we will get accustomed. Comparative Literature and Language, 35(3), 217-235.

Seidman, S. (2013). Contention of votes in the sociology. Translation by Hadi Jalili, Tehran: Ney Publishing.

Shahande, N. (2015, November 5). From word to image. Retrieved from Http://Silentlogos. blogspot.nl/2008/10/Blog-Post_22.html

Storm, M. (2015). Spanish-language print media in the USA: A social semiotics analysis of ideological representations in photojournalism. Social Semiotics, 26(2), 151-169.

Thomas, P. (2014). Christian Fundamentalism and Media, Translated Masoud Shah Hosseini. Communications Management, 54, 76-79.

Van Leeuwen, T. (2005). Introducting Social Semiotics. New York: Routledge.

Vannini, P. (2007). Social semiotic and fieldwork method and analysis. Royal University Victoria, 13(1), 113-140.

Weinberg, L., \& Pedahzur, A. (2005). Religious fundamentalism and political extremism. United States: Frank Cass.

Winkler. C., \& Dauber. C. E. (2014). Visual propaganda and extremism in the online environment. United State: Strategic Studies Institute and U.S. Army War College Press. 